\title{
PSYCHOMETRIC PROPERTIES OF THE INTERNALIZED STIGMA OF MENTAL ILLNESS SCALE ADAPTED FOR PEOPLE WHO USE PSYCHOACTIVE SUBSTANCES.
}

\author{
Verónica del Valle Gallo', María Soledad Burrone', Alicia Ruth Fernández', Jennifer E. Boyd², \\ Roberto Ariel Abeldaño3.
}

\begin{abstract}
Background: People who consume psychoactive substances may experience situations of social stigma on the part of the society in general, and also situations of internalized-stigma derived from their own consumption of substances. The Internalized Stigma of Mental Illness (ISMI) scale has been shown to be valid and reliable to evaluate the internalized-stigma in people with severe mental disorders, but in Argentina there is no a Spanish version of this scale for use with people who use psychoactive substances. The objective of this work was to evaluate the psychometric properties of the Spanish version of the Internalized Stigma of Mental Illness instrument adapted for people who use psychoactive substances.

Method: The work was carried out on a sample of 200 patients older than 18 years under treatment of rehabilitation by consumption of psychoactive substances in a public institution of the city of Córdoba (Argentina) between the years 2014 and 2016. The instrument used was the Internalized Stigma of Mental Illness (ISMI) previously adapted for use in these groups of patients. It was determined the reliability of the scale through Cronbach's coefficients $\alpha$ and factorial structure was analyzed through an exploratory factor analysis.

Results: The obtained coefficients showed a high reliability, while in the factorial structure emerged the 4 theoretical dimensions described by Ritsher, namely: social isolation, perceived discrimination, alienation and stereotyping.

Conclusion: It is concluded that the scale adapted for people who use psychoactive substances is reliable and with an adequate factorial structure.
\end{abstract}

Keywords: social stigma, stigmatization, substance-related disorders, public health, mental health.

1. Facultad de Ciencias Médicas. Universidad Nacional de Córdoba, Argentina.

2. Health Service, San Francisco VA Health Care System. Department of Psychiatry, University of California. San Francisco. USA.

3. División de Estudios de Posgrado. Universidad de la Sierra Sur. México.

Corresponding author: Dr. Roberto Ariel Abeldaño. Universidad de la Sierra Sur. Guillermo Rojas Mijangos S/N . Col. Ciudad Universitaria, CP. 70800. Miahuatlán de Porfirio Díaz, Oaxaca, Mexico. ariabeldanho@gmail.com 


\section{Introduction}

The Internalized Stigma of Mental IIIness (ISMI) scale developed by Ritsher ${ }^{(1)}$ has been used in studies on severe mental disorders ${ }^{(2)}$, it was validated in various countries and in several languages ${ }^{(3)}$. Apart from the scope of the mental health, it has also been used in other clinical situations ${ }^{(4)}$. In USA ${ }^{(5)}$ and Brazil (6) this same scale has been adapted to assessing internalized-stigma in people consuming substances.

In the Latin American context, studies of cons

truction and validation of instruments to assessing internalized-stigma represent a real step forward in the knowledge, because these instruments provide greater depth in the understanding of the factors related to the impact on the everyday life of the person who consumes substances, driving strategies aimed at the reduction of social isolation and to consolidate the treatment of these persons ${ }^{(7)}$.

The aim was to assess the psychometric properties of the Spanish version of the ISMI scale adapted for people who use psychoactive substances.

\section{Methods}

The study was cross-sectional, developed in the Provincial Institute of Alcoholism and Drug Addiction in Córdoba (Argentina) between October 2014 and May 2016.

The universe was composed of patients older than 18 years, under rehabilitation treatment by consumption of psychoactive substances. The sample was intentional to cover the quota of 200 patients presented in this study.

The inclusion criteria for the sample were:

- Having 18 or more years of age.

- Being under treatment of rehabilitation by consumption of psychoactive substances.

-Accepting voluntarily participate in the study.

The only exclusion criterion was to be in a phase of acute intoxication by abuse of psychoactive substances at the time of the implementation of the instrument.

For assessing of internalized stigma, it was used the ISMI scale (1), translated into Latin-American Spanish in Mexico ${ }^{(8)}$. In Córdoba, the instrument had a semantic adaptation to be used in this study group.

The scale has 29 items grouped in five sub-scales: -Alienation: six items.

-Stereotype endorsement: seven items.

-Perceived Discrimination: five items.

-Social withdrawal: six items.

-Stigma Resistance: five items.

All items are scored on a 4-point Likert scale (1=Strongly Disagree; 2=Disagree; 3=Agree; 4=Strongly agree).

The level of stigma is determined in accordance with the recommendations of Lysaker (9), by calculating the mean of each item of the scale in the sample, assuming as indicators of stigma the following averages for each item:

1.00 to 2.00: without internalized-stigma

2.01 to 2.50: mild internalized-stigma

2.51 to 3.00: moderate internalized-stigma

3.01 to 4.00: severe internalized-stigma.

The research project was approved by the "Board of Ethical Review in Cordoba". In all cases we used an approved informed consent form.

Reliability was analyzed following the technique of internal consistency by the Cronbach's a coefficient and the Spearman-Brown coefficient -obtained by Split Half- (10). The factorial structure was determined by maximum likelihood factor analysis, extracting 4 factors forced with 24 items, excluding sub-scale "Stigma Resistance" as recommended by Ritsher ${ }^{(1)}$.

\section{Results}

200 patients were surveyed at the Provincial Institute of Alcoholism and Drug Addiction. The average age of the patients was 37.3 (SD 12.6) years. The average age of onset of substances was 19.4 years (SD 7.4); while the treatment time by consumption of substances which declared the patients was from 1 month to 20 years. In relation to the type of consumption, $35.6 \%$ consume only alcohol and $64.4 \%$ reported alcohol and other substances (poly-consumption).

In Table 1 we present the mean scores of items, which ranged between 2.15 and 3.38 points, with standard deviations that ranged between 0.81 and 1.01. The total scores of the scale in this sample of patients presented an average of 74.1 (SD 15.5). 


\begin{tabular}{|c|c|c|}
\hline Ítems & Mean & SD \\
\hline I feel out of place in the world because I use drugs/alcohol & 2.53 & .890 \\
\hline Drugs/alcohol use has spoiled my life & 2.93 & .863 \\
\hline People who doesn't use drugs/alcohol could not possibly understand me & 2.75 & .805 \\
\hline I am embarrassed or ashamed that I use drugs/alcohol & 2.85 & .910 \\
\hline I feel inferior to others who do not use drugs/alcohol & 2.37 & .997 \\
\hline I am disappointed in myself for using drugs/alcohol & 3.00 & .938 \\
\hline Stereotypes about drug/alcohol users apply to me & 2.47 & .819 \\
\hline People can tell that I use drugs/alcohol by the way I look & 2.45 & .943 \\
\hline People who use drugs/alcohol tend to be violent & 2.58 & .828 \\
\hline Because I use drugs/alcohol, I need others to make most decisions for me & 2.24 & .896 \\
\hline People who use drugs/alcohol can't live a good, rewarding life & 2.89 & .969 \\
\hline People who use drugs/alcohol should not get married & 2.15 & .974 \\
\hline I can't contribute anything to society because I use drugs/alcohol & 2.29 & 1.003 \\
\hline People discriminate against me because I use drugs/alcohol & 2.67 & .918 \\
\hline Others think that I can't achieve much in life because I use drugs/alcohol & 2.67 & .838 \\
\hline People ignore me or take me less seriously just because I use drugs/alcohol & 2.59 & .815 \\
\hline People often patronize me, or treat me like a child, just because I use drugs/alcohol & 2.42 & .875 \\
\hline Nobody would be interested in getting close to me because I use drugs/alcohol & 2.37 & .924 \\
\hline I don't talk about myself much because I don't want to burden others with my use of drugs/alcohol & 2.60 & .939 \\
\hline I don't socialize as much as I used to because my use of drugs/alcohol might make me look or behave "weird" & 2.61 & .990 \\
\hline Negative stereotypes about using drugs/alcohol keep me isolated from the "normal" world & 2.25 & .865 \\
\hline I stay away from social situations in order to protect my family or friends from embarrassment & 2.16 & .891 \\
\hline I avoid getting close to people who don't use drugs/alcohol to avoid rejection & 2.23 & .870 \\
\hline Being around people who don't use drugs/alcohol makes me feel out of place or inadequate & 2.22 & .832 \\
\hline I feel comfortable being seen in public with a person who obviously uses drugs/alcohol & 2.65 & .899 \\
\hline In general, I am able to live life the way I want to & 2.24 & .896 \\
\hline I can have a good, fulfilling life, despite my use of drugs/alcohol & 2.70 & 1.015 \\
\hline People who use drugs/alcohol make important contributions to society & 2.90 & .911 \\
\hline Living with use of drugs/alcohol has made me a tough survivor & 3.38 & .835 \\
\hline
\end{tabular}

Table 1. Mean and standard deviation of scores for each item in the total sample of patients ( $n=200$ ). IPAD, Córdoba. Years 2014-2016.

$\begin{array}{lc}\text { Sub-scale } & \text { ISMI Cronbach's } \boldsymbol{\alpha} \\ \text { Alienation } & .84 \\ \text { Stereotype endorsement } & .77 \\ \text { Perceived Discrimination } & .84 \\ \text { Social Withdrawal } & .87 \\ \text { Stigma Resistance } & .66 \\ 24 \text { items scale } & .94 \\ 29 \text { items scale } & .93 \\ \text { Spearman-Brown coefficient (Split Half) } 24 \text { items } & .92 \\ \text { Spearman-Brown coefficient (Split Half) } 29 \text { items } & .91\end{array}$

Table 2. Statistical internal consistency of the subscales and total scale of the ISMI. ( $n=200)$. IPAD, Córdoba. Years 2014-2016. 
From there, it appears that the main elements of internalized-stigma (scores above an average of 2.5) were the items: $1,2,3,5,7,8,9,10,11,14$, 17, 21, 22, 24, 27 and 28).

The values of Cronbach's $\alpha$ obtained in the subscales ranged between 0.66 and 0.87 points, the sub-scale with the lowest score was "stigma resistance".

Versions of 24 items and 29 items were tested, getting Cronbach's $\alpha$ of 0.94 and 0.93 , respectively. Spearman-Brown coefficients for the scales of 24 and 29 items were 0.92 and 0.91 , respectively (Table 2 ).

The measure of sampling adequacy of KaiserMeyer-Olkin (KMO) showed a value of 0.908 ;
Bartlett's Test was significant $(p<0.001)$ and the correlations matrix revealed that the variables are highly correlated, therefore it was assumed that the factor analysis is appropriate to analyze the underlying structure of the data.

From these preliminary tests, it was decided to define a model of maximum likelihood factor analysis with a forced extraction of 4 orthogonal factors (Varimax). The variables entered into the model were the original 24 suggested by the original publication of Ritsher (1), which excludes the subscale of stigma resistance due to their low coefficients of reliability.

The 4 factors accumulated a $53.4 \%$ resulting from the total variance explained, according to the fo-

\begin{tabular}{cccc}
\multicolumn{4}{c}{ Factor } \\
$\mathbf{1}$ & $\mathbf{2}$ & $\mathbf{3}$ & $\mathbf{4}$ \\
.76 & & & \\
.71 & & & \\
.63 & & & .48 \\
.51 & & & \\
.51 & & .43 &
\end{tabular}

People can tell that I use drugs/alcohol by the way I look

People ignore me or take me less seriously just because I use drugs/alcohol $\quad .82$

People discriminate against me because I use drugs/alcohol $\quad .62$

Others think that I can't achieve much in life because I use drugs/alcohol $\quad .60$

Because I use drugs/alcohol, I need others to make most decisions for me $\quad .48$

$\begin{array}{ll}\text { Stereotypes about drug/alcohol users apply to me } & 46\end{array}$

People who use drugs/alcohol tend to be violent $\quad .43$

People who doesn't use drugs/alcohol could not possibly understand me

People often patronize me, or treat me like a child, just because I use drugs/alcohol

I can have a good, fulfilling life, despite my use of drugs/alcohol $\quad .68$

I am disappointed in myself for using drugs/alcohol $\quad .61$

I am embarrassed or ashamed that I use drugs/alcohol $\quad .60$

Drugs/alcohol use has spoiled my life $\quad .46 \quad .59$

I don't talk about myself much because I don't want to burden others with my use of drugs/alcohol

I don't socialize as much as I used to because my use of drugs/alcohol might make me look or behave $\quad .44 \quad .48$

"weird"

People who use drugs/alcohol make important contributions to society $\quad .58$

People who use drugs/alcohol should not get married $\quad .52$

Nobody would be interested in getting close to me because I use drugs/alcohol $\quad .44$

I feel inferior to others who do not use drugs/alcohol drogas/alcohol

Table 3. Exploratory factor analysis of the 24 items of the ISMI adapted version for consumers of psychoactive substances (Loads $\geq 0.40$ are shown) (n=200). IPAD, Córdoba. Years 2014-2016. 
llowing detail: The first factor explained $15.5 \%$, the second factor explained $15.2 \%$, the third factor $13 \%$ and the fourth factor the $9.5 \%$.

The first factor grouped 5 items, while the second and third factor grouped 6 items each and the fourth factor grouped 3 items. Items 15, 16, 18 and 21 had a low factor loading $(<0.40)$, while there were 5 items that loaded on 2 factors simultaneously (Table 3).

In this analysis emerged the 4 theoretical dimensions described by Ritsher (1), as the first factor contained 4 items from the "social withdrawal" sub-scale, the second factor contained 3 items corresponding to the "perceived discrimination" sub-scale, the third factor included 3 items from the "alienation" sub-scale and the fourth factor contained 2 items from the "stereotype endorsement" sub-scale.

The item-test correlation was greater than 0.40 , it is assumed that the analysis of the factor structure of the scale has proved successful with this sample.

\section{Discussion}

From the layout of an instrument widely used in different languages and versions ${ }^{(11)}$ to determine the internalized-stigma in people with mental disorders, this study concludes with the adaptation of the instrument in people who consume psychoactive substances.

The scores of internalized-stigma in this sample were higher than those observed by other authors in patients with mental disorders ${ }^{(1,12-14)}$; while there is a similar behavior when compared to the Taft version (15) who applied in patients with inflammatory bowel disease, or the study of Stevelink (4) who applied in people living with HIVIAIDS and leprosy.

In populations with similar characteristics of consumption, it was noted that the stigma in the sample of Cordoba was substantially higher than the observed by Luoma ${ }^{(16)}$; while there were scores similar to that observed by Soares ${ }^{(6)}$ in Brazil. This would be suggesting the presence of cultural factors specific to each place related to the presence of stigma.

Regarding the reliability of the scale, the obtained coefficients were coincident with previously noted in the original study of Ritsher (1) and other versions ${ }^{(3,11-13,15)}$, including versions of Luoma and Soares with people with substance use ${ }^{(5,6)}$, where the "Stigma resistance" sub-scale had less reliability.

In the factor analysis, 12 items kept factorial groupings similar to those of the original scale ${ }^{(1)}$, but at the same time turned out to be different from what has been observed in the scale adapted by Soares ${ }^{(6)}$.

This study did not include an instance of re-test; therefore it is recommended that future research will enquire the temporal stability of the scale. In conclusion, we can say that this adapted version of the ISMI for people who use psychoactive substances was reliable and its psychometric properties were satisfactory.

All authors declare no conflicts of interest.

The research project was funded by National Ministry of Health, Argentina.

\section{References}

1. Ritsher JB, Otilingam PG, Grajales M. Internalized stigma of mental illness: psychometric properties of a new measure. Psychiatry Res [Internet]. 2003 Nov 1;121(1):31-49. Available from: http://www.ncbi.nlm. nih.gov/pubmed/14572622

2. Botha UA, Koen L, Niehaus DJH. Perceptions of a South African schizophrenia population with regards to community attitudes towards their illness. Soc Psychiatry Psychiatr Epidemiol [Internet]. 2006 Aug;41(8):619-23. Available from: http://www.ncbi. nlm.nih.gov/pubmed/16733630

3. Hwang T-Y, Lee W-K, Han E-S, Kwon U-J. A Study on the Reliability and Validity of the Korean Version of Internalized Stigma of Mental IIIness Scale (KISMI). Korean Neuropsychiatr Assoc. 2006;45(5):41826.

4. Stevelink SAM, van Brakel WH, Augustine V. Stigma and social participation in Southern India: differences and commonalities among persons affected by leprosy and persons living with HIVIAIDS. Psychol Health Med [Internet]. 2011 Dec;16(6):695-707. Available from: http://www.ncbi.nlm.nih.gov/pubmed/21391136

5. Luoma J, Kohlenberg B, Hayes S, Bunting $K$, Rye A. Reducing self-stigma in substance abuse through acceptance and commitment therapy: Model, 
manual development, and pilot outcomes. Addict Res Theory. 2008;16(2):149-65.

6. Soares RG, Santos P, Ana S, Noto R, Boyd JE. Validação da Versão Brasileira da Escala ISMI Adaptada para Dependentes de Substâncias. Psicol Teoría e Pesqui [Internet]. 2015;31(2):229-38. Available from: http://dx.doi.org/10.1590/010237722015021093229238

7. Soares RG, Nery FC, Noto AR, Silveira $P S$, Ronzani TM. A Mensuração do Estigma Internalizado : Revisão Sistemática da Literatura. Psicol em Estud. 2011;16(4):635-45.

8. Mora-Rios J, Bautista-aguilar N, Natera G, Pedersen D. Adaptación cultural de instrumentos de medida sobre estigma y enfermedad mental en la Ciudad de México. Salud Ment. 2013;36(1):9-18.

9. Lysaker PH, Roe D, Yanos PT. Toward understanding the insight paradox: internalized stigma moderates the association between insight and social functioning, hope, and self-esteem among people with schizophrenia spectrum disorders. Schizophr Bull [Internet]. 2007 Jan;33(1):192-9. Available from: http:// www.ncbi.nlm.nih.gov/pubmed/16894025

10. Cárdenas SFS. Coeficientes de confiabilidad de instrumentos escritos en el marco de la teoría clásica de los tests. Rev Cuba Educ Medica Super. 2009;22(2):1-14.
11. Boyd JE, Adler EP, Otilingam PG, Peters T. Internalized Stigma of Mental IIIness (ISMI) scale: a multinational review. Compr Psychiatry [Internet]. 2014 Jan;55(1):221-31. Available from: http://www.ncbi.nlm. nih.gov/pubmed/24060237

12. Chang C-C, Wu T-H, Chen C-Y, Wang J-D, Lin $C-Y$. Psychometric evaluation of the internalized stigma of mental illness scale for patients with mental illnesses: measurement invariance across time. PLoS One [Internet]. 2014;9(6):e98767. Available from: http:// www.ncbi.nlm.nih.gov/pubmed/24887440

13. Ersoy MA, Varan A. Reliability and validity of the Turkish version of the internalized stigma of mental illness scale. Turk Psikiyatri Derg [Internet]. 2007;18(2):163-71. Available from: http://www.ncbi. nlm.nih.gov/pubmed/17566882

14. Sibitz I, Friedrich ME, Unger A, Bachmann A, Benesch T, Amering M. Internalized Stigma of Schizophrenia: Validation of the German Version of the Internalized Stigma of Mental IIIness-Scale (ISMI). Psychiatr Prax [Internet]. 2013 Mar;40(2):83-91. Available from: http://www.ncbi.n/m.nih.gov/pubmed/23354628

15. Taft TH, Ballou S, Keefer L. A preliminary evaluation of internalized stigma and stigma resistance in inflammatory bowel disease. J Health Psychol [Internet]. 2013 Apr;18(4):451-60. Available from: http:// www.ncbi.nlm.nih.gov/pubmed/22689587 